\title{
ANATOMIA DAS MADEIRAS DE CAMPOMANESIA AUREA O. BERG E EUGENIA MYRCIANTHES NIEDENZU (MYRTACEAE) ${ }^{1}$
}

\author{
JOSÉ NEWTON CARDOSO MARCHIORI² SIDINEI RODRIGUES DOS SANTOS ${ }^{3}$
}

\section{RESUMO}

São anatomicamente descritas as madeiras de Campomanesia aurea O. Berg e Eugenia myrcianthes Niedenzu, com base em amostras procedentes do Rio Grande do Sul. Campomanesia aurea apresenta raios mais largos, com 1 - 4 células, e parênquima axial difuso-em-agregados. Em Eugenia myrcianthes, por sua vez, os raios são estreitos (1 - 2-seriados) e o parênquima apotraqueal é predominantemente em faixas.

Palavras-chave: Campomanesia aurea, Eugenia myrcianthes, Hexachlamys edulis, anatomia da madeira, Myrtaceae.

\section{SUMMARY}

[Wood anatomy of Campomanesia aurea O. Berg and Eugenia myrcianthes Niedenzu (Myrtaceae)].

The woods of Campomanesia aurea O. Berg and Eugenia myrcianthes Niedenzu are anatomically described, based on samples from Rio Grande do Sul state, Brazil. Campomanesia aurea shows diffuse-in-aggregates axial parenchyma and rays with 1 to 4 cells wide. Eugenia myrcianthes, on the other hand, has thinner rays $(1-2$ cells wide) and axial parenchyma in narrow bands, up to three cells wide.

Key words: Campomanesia aurea, Eugenia myrcianthes, Hexachlamys edulis, wood anatomy, Myrtaceae.

\section{INTRODUÇÃO}

$\mathrm{O}$ presente estudo visa à descrição microscópica da madeira de duas espécies de Mirtáceas da flora sul-rio-grandense.

Conhecida popularmente como guabirobeira-do-campo (Backes \& Nardino, 2001), Campomanesia aurea $\mathrm{O}$. Berg é nativa na $\mathrm{Ar}$ gentina, Paraguai, Uruguai e Brasil, do Paraná ao Rio Grande do Sul (Landrum, 1986). Subarbusto de até $1,5 \mathrm{~m}$ de altura, apresenta folhas ovadas ou elípticas, discolores, de textura cartácea ou coriácea, bordo inteiro e frutos globosos $(8-10 \mathrm{~mm})$, amarelos ou alaranjados quando maduros. No Rio Grande do Sul, é fre-

\footnotetext{
${ }^{1}$ Recebido para publicação em 10-I-2010 e aceito para publicação em 21-IV-2010.

2 Engenheiro Florestal, Dr., bolsista de Produtividade em Pesquisa (CNPQ - Brasil), Prof. Titular do Departamento de Ciências Florestais, Universidade Federal de Santa Maria. Santa Maria, RS, Brasil. marchiori@pq.cnpq.com.br

3 Biólogo, bolsista (CNPQ - Brasil), doutorando do Programa de Pós-Graduação em Eng. Florestal, Departamento de Ciências Florestais, Universidade Federal de Santa Maria.sthurt.bio@gmail.com
}

qüente em campos rupestres da Campanha, Depressão Central, Serra do Sudeste e Campos de Cima da Serra (Sobral, 2003). A madeira, ainda desconhecida sob o ponto de vista anatômico, carece de utilização devido ao tamanho reduzido dos caules.

Eugenia myrcianthes Niedenzu, o popular pêssego-do-mato (Mattos, 1983), é freqüentemente referido na literatura botânica como Hexachlamys edulis O. Berg, binômio atualmente reduzido à sinonímia. Trata-se de árvore caducifólia de até $12 \mathrm{~m}$ de altura, nativa da Bolívia, Paraguai, Argentina, Uruguai e Brasil, do Mato Grosso ao Rio Grande do Sul (Legrand \& Klein, 1977); neste Estado, habita na metade sul, bem como em campos arenosos da região litorânea e lacustre (Marchiori \& Sobral, 1997). Além de ornamental, a espécie produz frutos comestíveis relativamente grandes $(15-30 \mathrm{~mm})$, comparados ao restante da família. A madeira, desconhecida anatomicamente, é moderadamente pesada, dura, compacta e resistente, indicada para cabos de ferramentas, obras internas e marcenaria comum (Lorenzi, 1992). 


\section{REVISÃO DE LITERATURA}

Apesar do grande número de espécies nativas e da importância fitofisionômica das Mirtáceas nas florestas sul-brasileiras (Klein, 1984), são ainda escassos os estudos anatômicos sobre madeiras desta família botânica.

Para o gênero Campomanesia, Metcalfe \& Chalk (1972) destacam: poros em número de 5 - 20/ $\mathrm{mm}^{2}$; vasos solitários de diâmetro médio, em linhas oblíquas; e raios heterogêneos, com $4-6$ células de largura e $1-3$ fileiras marginais de células quadradas e eretas. Das espécies nativas, dispõe-se de estudo descritivo do lenho jovem (Rodrigues, 2005) e madeira (Santos \& Marchiori, 2009c) de Campomanesia xanthocarpa, bem como da madeira de Campomanesia guazumaefolia (Marchiori, 1998).

Para Campomanesia xanthocarpa, Santos \& Marchiori (2009c) salientam a baixa frequiência de poros $\left(<25 / \mathrm{mm}^{2}\right)$, o parênquima axial difuso-em-agregados, tendente a escalariforme e os raios relativamente largos ( $1-5$ células), de dois tamanhos distintos, sendo que, nos multisseriados, as margens são geralmente mais curtas do que o corpo central.

Para Campomanesia guazumaefolia, Marchiori (1998) refere, entre outros aspectos: poros extremamente numerosos, muito pequenos a pequenos; elementos vasculares muito curtos a longos, com espessamentos espiralados e pontoações ornamentadas na parede; placas de perfuração simples; parênquima apotraqueal; raios heterogêneos, com abundante conteúdo; fibras com pontoações areoladas; e ausência de traqueídeos vasicêntricos e cristais.

Gênero com número maior de espécies, Eugenia L. conta, igualmente, com literatura anatômica mais abundante.

Para duas espécies da Floresta Atlântica, Soffiatti \& Angialossy-Alfonso (1999) relacionam: porosidade difusa; vasos solitários; placas de perfuração simples; pontoações inter- vasculares alternas e guarnecidas; parênquima apotraqueal seriado; raios heterogêneos, estreitos; fibras de pontoações areoladas, com paredes espessas a muito espessas; e traqueídeos vasicêntricos, presentes. Com pouca variação anatômica, a separação de ambas as espécies foi estabelecida com base no arranjo do parênquima axial e na presença de cristais.

Em estudo de Eugenia copacabanensis, E. cuprea e E. macahensis, Marques et al. (2007) também encontraram estrutura anatômica homogênea sob o ponto de vista qualitativo, diferindo as três espécies pelo arranjo do parênquima axial e agrupamento de vasos.

Da flora sul-rio-grandense, foram descritas as madeiras de Eugenia involucrata (Marchiori, 1984), Eugenia mansoi (Santos \& Marchiori, 2009a), Eugenia uniflora (Santos \& Marchiori, 2009b), Eugenia uruguayensis e Eugenia rostrifolia (Marchiori \& Santos, 2010).

Para Eugenia mansoi, Marchiori \& Santos (2009a) destacaram a ausência de ornamentos em pontoações, o parênquima axial difuso-emagregados e em linhas tangenciais, e as fibras com pontoações areoladas. Para Eugenia uniflora, Santos \& Marchiori (2009b) salientaram o parênquima apotraqueal em faixas, as fibras de paredes muito espessas e a abundância de séries cristalíferas. As madeiras de Eugenia rostrifolia e Eugenia uruguayensis, por sua vez, foram distinguidas com base no arranjo de poros e parênquima axial: a identificação da primeira levou em conta o parênquima cristalífero, o alinhamento tangencial de poros nos limites de anéis, a presença de poros em numerosos múltiplos radiais e cachos, e o parênquima axial em faixas de até 5 células de espessura; a segunda espécie separa-se pelos anéis delimitados por fibras radialmente estreitas, pelos poros exclusivamente solitários e pelo parênquima axial nos arranjos apotraqueais difuso, difuso-em-agregados e paratraqueal escasso, mas não em faixas tangenciais (Marchiori \& Santos, 2010). 


\section{MATERIAL E MÉTODOS}

O material em estudo consiste de duas amostras de madeira e respectivo material botânico, conservados no Herbário do Departamento de Ciências Florestais (HDCF) da Universidade Federal de Santa Maria com os seguintes registros:

- Campomanesia aurea. Marchiori, J.N.C., n. 421; São Vicente do Sul, RS, 01-VIII-1986. HDCF n. 2400.

- Eugenia myrcianthes. Santos, S.R. dos, s/ n; Barra do Quaraí, RS, 26-XI-2008. HDCF n. 5916.

Para o estudo anatômico das madeiras foram preparadas lâminas de cortes anatômicos e de macerado. Do material lenhoso foram extraídos três corpos-de-prova da parte mais externa do lenho, próxima ao câmbio, orientados para a obtenção de cortes anatômicos nos planos transversal, longitudinal radial e longitudinal tangencial. Um quarto bloquinho foi também preparado, com vistas à maceração.

Na microtomia, seguiu-se a técnica padrão: amolecimento dos corpos-de-prova por fervura em água e realização de cortes em micrótomo de deslizamento, regulado na espessura nominal de $20 \mu \mathrm{m}$. Os cortes anatômicos foram tingidos com acridina-vermelha, crisoidina e azul de astra (Dujardin, 1964), desidratados em série alcoólica crescente $(30 \%, 50 \%, 75 \%, 90 \%$, $95 \%$, duas vezes álcool absoluto), diafanizados em xilol e montados em lâminas permanentes, com "Entellan".

Na maceração, seguiu-se o método de Jeffrey (Burger \& Richter, 1991), colorindo-se a pasta de fibras com safranina 1\%; a montagem de lâminas seguiu o anteriormente descrito, com a diferença de que as três primeiras etapas foram desenvolvidas com o uso de papel de filtro.

A descrição microscópica das madeiras baseou-se nas recomendações do IAWA Comitee (1989). No caso da percentagem dos tecidos, foram realizadas 600 determinações ao acaso, com auxílio de contador de laboratório, conforme proposto por Marchiori (1980). A frequiên- cia de poros foi obtida de forma indireta, usando-se um quadrado de área conhecida superposto a fotomicrografias de seções transversais das madeiras. As medições foram realizadas em microscópio Carl Zeiss dotado de ocular de escala graduada, no Laboratório de Anatomia da madeira da Universidade Federal de Santa Maria.

$\mathrm{Na}$ citação de características quantitativas, os números entre parênteses equivalem aos valores mínimos e máximos observados; o valor que acompanha a média é o desvio padrão.

As fotos foram tomadas em microscópio Olympus cx40, equipado com câmera digital Olympus Camedia C3000.

\section{DESCRIÇÕES ANATÔMICAS \\ 1 - Campomanesia aurea O. Berg}

Anéis de crescimento: distintos, delimitados por camada de fibras radialmente estreitas no lenho tardio e, por vezes, pela maior concentração e alinhamento tangencial de poros no início do anel (Figura 1A).

Vasos: numerosos a muito numerosos $(51 \pm$ $27(37-100)$ poros $\left./ \mathrm{mm}^{2}\right)$, ocupando $9,5 \pm 3,6 \%$ do volume da madeira. Porosidade difusa. Poros exclusivamente solitários, circulares, ovais até ligeiramente poligonais, muito pequenos ( 28 $\pm 9(12-45) \mu \mathrm{m})$, de paredes finas $(2 \pm 0,2(1,5$ $-2,6) \mu \mathrm{m})$ e sem padrão definido de organização (Figura 1A, B). No início do anel de crescimento, os poros dispõem-se, por vezes, em alinhamento tangencial, são mais numerosos e com freqüentes contatos laterais. Elementos vasculares de comprimento médio (361 \pm 91 $(170-560) \mu \mathrm{m})$, com placas de perfuração simples, geralmente oblíquas e com apêndices em ambas as extremidades. Pontoações intervasculares alternas, circulares, raramente ovais $(5 \pm 0,7(4-6) \mu \mathrm{m})$, com abertura em fenda inclusa, ornamentada. Pontoações raio-vasculares com aréolas distintas, semelhantes às intervasculares, porém menores $(4-0,7(3-5) \mu \mathrm{m}) \mathrm{e}$ restritas às margens de raios. Espessamentos espiralados e conteúdos, ausentes. 

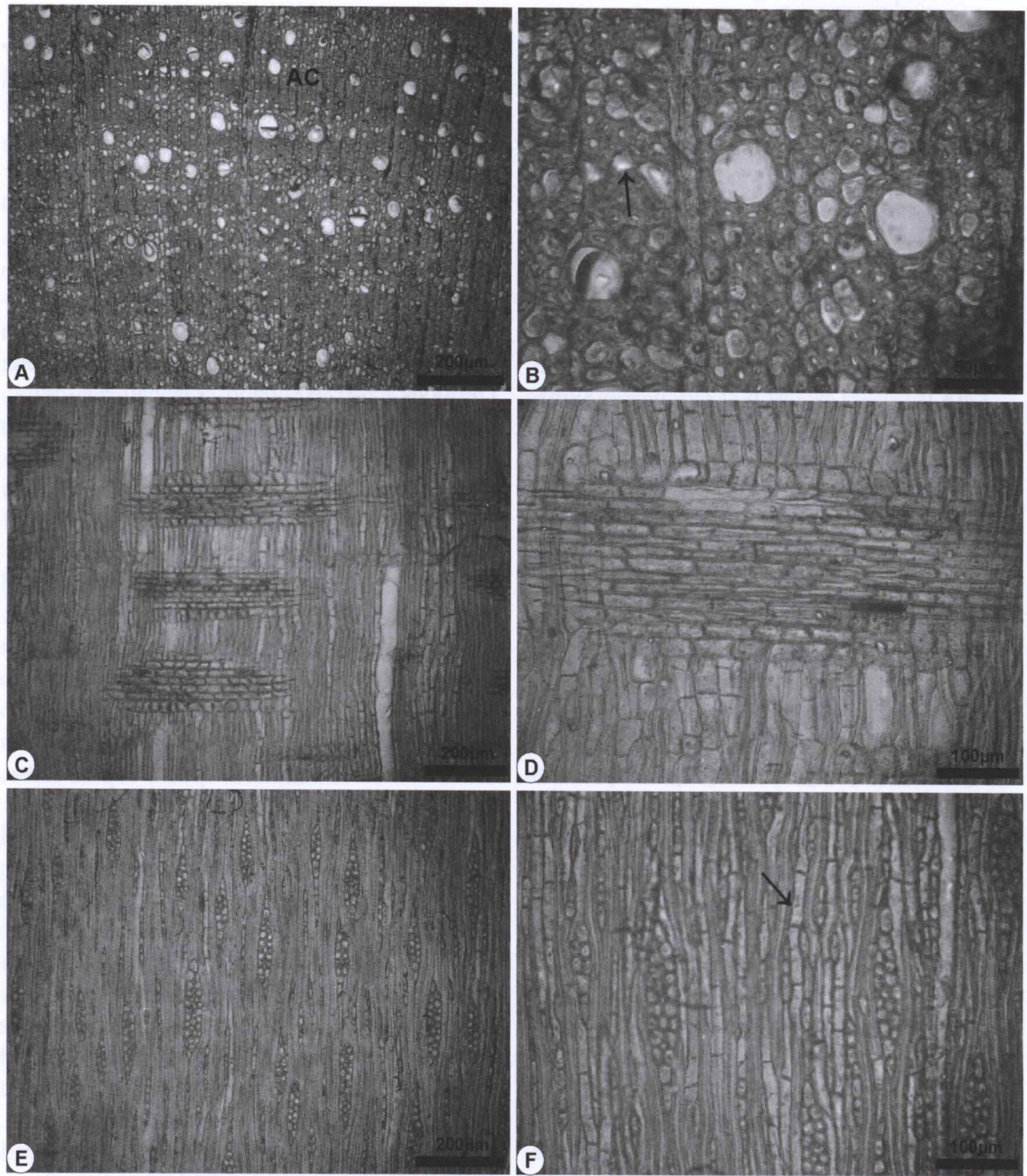

FIGURA 1 - Aspectos anatômicos da madeira de Campomanesia aurea. A - Porosidade difusa, vasos solitários e anéis de crescimento distintos, marcados por camada de fibras radialmente estreitas (AC), em seção transversal. B - Mesmo plano anatômico da foto anterior, mostrando vasos arredondados até poligonais, fibras de paredes finas a espessas e parênquima apotraqueal difuso e difuso-em-agregados (seta). C - Raios heterogêneos, com células procumbentes, no corpo central, e margens de células quadradas, eretas ou procumbentes mais altas do que as do corpo central (seção longitudinal radial. D - Detalhe de seção longitudinal radial, destacando células quadradas e procumbentes mais altas, nas margens de raio multisseriado. E - Raios de dois tamanhos distintos, em seção longitudinal tangencial. F - Fibras, parênquima axial (seta), vasos e raios de dois tamanhos distintos, em seção longitudinal tangencial. 
Parênquima axial: muito distinto das fibras em corte transversal, representando $23 \pm 3 \%$ do volume da madeira; em arranjos apotraqueal difuso e, principalmente, difuso-em-agregados, além de paratraqueal escasso (Figura 1A, B). Séries parenquimáticas de $294 \pm 74$ (145 - 438) $\mu \mathrm{m})$ e $2-4$ células de altura (Figura 1F). Inclusões minerais e conteúdos, ausentes.

Raios: muito numerosos $(19 \pm 1,8(16-21)$ raios/mm), com $1-3$, raro 4 células de largura e de dois tamanhos distintos (Figura 1E, F), ocupando $18,5 \pm 2 \%$ do volume da madeira. Raios multisseriados de $213 \pm 52(130-310)$ $\mu \mathrm{m}$ e 7 - 13 (16) células de altura; heterogêneos, reúnem células procumbentes, na parte multisseriada, e $1-4$ (6) fileiras marginais de células quadradas, eretas e procumbentes, semelhantes ou pouco mais altas do que nas margens unisseriadas (Figura 1D, E). Os unisseriados, de $113 \pm 59(40-290) \mu \mathrm{m} \mathrm{e} 1-4$ (8) células de altura. Raios axialmente fusionados, pouco freqüentes. Células envolventes e perfuradas, ausentes. Conteúdo de cor escura, escasso.

Fibras: com pontoações areoladas e aberturas cruzadas, presentes nas faces radiais e tangenciais da parede. Tecido fibroso representando 49,2 $\pm 3,6 \%$ do volume da madeira. Fibras curtas $(717 \pm 103(560-960) \mu \mathrm{m})$, com $14,5 \pm 2(12,5-20) \mu \mathrm{m}$ de largura e de paredes finas a espessas $(4 \pm 1(2-6) \mu \mathrm{m})$ (Figura 1B). Fibras septadas, fibras gelatinosas e espessamentos espiralados, ausentes. Traqueídeos vasicêntricos, presentes.

Outros caracteres: variantes cambiais, tubos laticíferos e taniníferos, canais intercelulares, máculas, células oleíferas, células mucilaginosas, estratificação e cristais, ausentes.

\section{2 - Eugenia myrcianthes Niedenzu}

Anéis de crescimento: distintos, delimitados por fibras radialmente estreitas (Figura 1A).

Vasos: muito numerosos (52 $\pm 7(44-62)$ poros $/ \mathrm{mm}^{2}$ ), ocupando $16,7 \pm 3,6 \%$ do volume da madeira. Porosidade difusa. Poros exclusivamente solitários, circulares a ovais, pequenos
$(52 \pm 9(28-70) \mu \mathrm{m})$, de paredes espessas $(4 \pm$ $0,8(2,5-5) \mu \mathrm{m})$ e sem padrão definido de organização (Figura 1A, B). Elementos vasculares de comprimento médio $(526 \pm 113(300-740)$ $\mu \mathrm{m})$, com placas de perfuração simples, geralmente oblíquas e apêndices em ambas as extremidades. Pontoações intervasculares alternas, circulares $(5,4 \pm 0,5(4,6-6,1) \mu \mathrm{m})$, com abertura em fenda inclusa, ornamentada. Pontoações raio-vasculares com aréolas distintas, semelhantes às intervasculares, porém menores $(3-0,2$ $(2,5-3,1) \mu \mathrm{m})$ e geralmente restritas à margem de raios. Espessamentos espiralados, ausentes. Conteúdo, escasso.

Parênquima axial: muito distinto das fibras em corte transversal, representando $18,7 \pm 3 \%$ do volume da madeira; em arranjo apotraqueal difuso, difuso-em-agregados e em faixas tangenciais irregulares, de até 5 células de largura, sobretudo no lenho inicial (Figura 1A, B); resta citar o padrão paratraqueal escasso, que é pouco freqüente. Séries parenquimáticas de 550 $\pm 119(342-750) \mu \mathrm{m}$ e $4-8$ (14) células de altura (Figura 1F). Cristais prismáticos, muito abundantes, em séries de até 26 câmaras não distendidas.

Raios: muito numerosos $(19 \pm 1,6(17-21)$ raios $/ \mathrm{mm}$ ), com $1-2$ células de largura (Figura $1 E)$, ocupando $13,2 \pm 3,2 \%$ do volume da madeira. Raios multisseriados de $261 \pm 61$ (160 410) $\mu \mathrm{m}$ e 5 - 15 , mais comumente 8 - 14 células de altura; heterogêneos, reúnem células procumbentes, na parte multisseriada, e $1-4$ (9) fileiras marginais de células quadradas, eretas e, menos freqüentemente, procumbentes mais altas do que no corpo central (Figura 1C). A parte multissseriada é geralmente mais curta do que as margens unisseriadas (Figura 1E, F). Os unisseriados, de $167 \pm 87(60-350) \mu \mathrm{m}$ e 1 - 6 (8) células de altura. Raios axialmente fusionados, freqüentes. Células radiais de paredes disjuntas, presentes. Inclusões minerais, células envolventes e células perfuradas, ausentes; grãos de amido, abundantes.

Fibras: com pontoações areoladas e aberturas geralmente cruzadas, presentes nas faces 

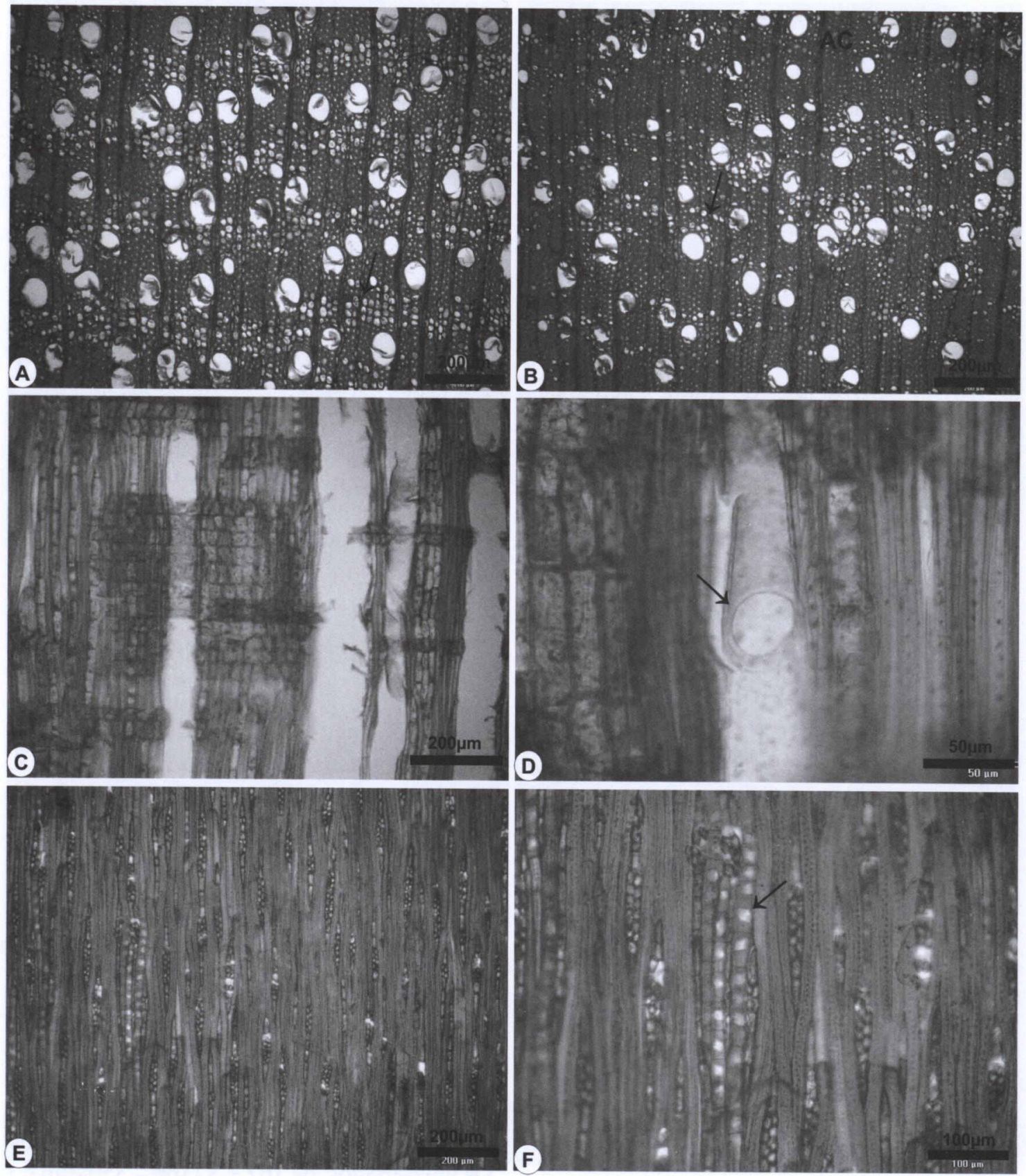

FIGURA 2 - Aspectos anatômicos da madeira de Eugenia myrcianthes. A - Porosidade difusa, vasos solitários, ovais, e parênquima apotraqueal em faixas (seta) de até 5 células de largura (seção transversal). B - Mesmo plano anatômico da foto anterior, destacando o parênquima axial, contrastante com fibras de paredes finas a espessas (seta), poros solitários e camada de fibras radialmente estreitas no limite do anel (AC). C - Raios heterogêneos, com células procumbentes, e várias fileiras marginais de células quadradas e eretas (seção longitudinal radial). D - Placa de perfuração simples, em seção longitudinal radial. E - Raios de corpo multisseriado mais curto do que as margens, em plano longitudinal tangencial. $\mathrm{F}$ - Mesmo plano anatômico da foto anterior, destacando cristais prismáticos em numerosas câmaras, no parênquima axial (seta). 
radiais e tangenciais da parede. Tecido fibroso representando $51,5 \pm 3 \%$ do volume da madeira. Fibras de comprimento médio (1154 \pm 143 $(880-1440) \mu \mathrm{m})$, com $18 \pm 2(15-23) \mu \mathrm{m}$ de largura e de paredes finas a espessas $(5 \pm 0,9$ (3 - 7) $\mu \mathrm{m}$ ) (Figura 1B). Fibras septadas, fibras gelatinosas e espessamentos espiralados, ausentes. Traqueídeos vasicêntricos, presentes.

Outros caracteres: variantes cambiais, tubos laticíferos e taniníferos, canais intercelulares, máculas, células oleíferas, células mucilaginosas e estratificação, ausentes.

\section{ANÁLISE DA ESTRUTURA ANATÔMICA}

As madeiras descritas apresentam diversos aspectos anatômicos em comum: porosidade difusa; vasos geralmente solitários, desprovidos de espessamentos espiralados; placas de perfuração simples; parênquima apotraqueal; raios heterogêneos; e fibras libriformes não septadas. Este conjunto de caracteres, de ocorrência generalizada em Mirtáceas (Metcalfe \& Chalk, 1972), foi igualmente comprovado por autores que pesquisaram em distintos gêneros botânicos desta família, representados na flora brasileira.

Para Campomanesia aurea, encontrou-se uma frequiência de poros nitidamente maior (51/ $\mathrm{mm}^{2}$ ) do que o referido, por Santos \& Marchiori (2009c), para Campomanesia xanthocarpa (18/ $\left.\mathrm{mm}^{2}\right)$; a presença de raios largos (1 - 4-seriados) e a predominância do parênquima difusoem-agregados, comprovados no material em estudo, parecem, todavia, ter valor diagnóstico para o gênero em questão.

No caso de Eugenia myrcianthes, o parênquima apotraqueal-em-faixas e a abundância de séries cristalíferas aproximam o material em estudo do descrito para Eugenia rostrifolia (Marchiori \& Santos, 2010), E. mansoi (Santos \& Marchiori, 2009a) e E. uniflora (Santos \& Marchiori, 2009b); Eugenia myrcianthes, todavia, distingue-se pelos raios mais finos (1 - 2seriados).

\section{REFERÊNCIAS BIBLIOGRÁFICAS}

BACKES, A.; NARDINO, M. Nomes populares $e$ científicos de plantas do Rio Grande do Sul. São Leopoldo: Ed. Unisinos, 2001. 202 p.

BURGER, L.M.; RICHTER, H.G. Anatomia da madeira. São Paulo: Ed. Nobel, 1991. 154 p.

DUJARDIN, E.P. Eine neue Holz-Zellulosenfaerbung. Mikrokosmos, n. 53, p. 94, 1964.

KLEIN, R.M. Importância sociológica das Mirtáceas em florestas rio-grandenses. Anais do XXXIV Congresso Nacional de Botânica (Porto Alegre), 1984. p. 367-375.

IAWA COMITTEE. IAWA list of microscopic features for hardwood identification. IAWA Bulletin, v. 10, n. 3, p. 218-359, 1989.

LANDRUM, L.R. Campomanesia, Pimenta, Blepharocalyx, Legrandia, Acca, Myrrhinium and Luma. Flora Neotropica, n. 45, p. 1-178, 1986.

LEGRAND, D.; KLEIN, R.M. Mirtáceas: Campomanesia, Feijoa, Britoa, Myrrhinium, Hexachlamys, Siphoneugena, Myrcianthes, Neomitranthes, Psidium. In: REITZ, P.R. (org.). Flora Ilustrada Catarinense. Itajaí: Herbário Barbosa Rodrigues, 1977. p. 571-730.

LORENZI, H. Árvores brasileiras: Manual de identificação e cultivo de plantas arbóreas nativas do Brasil. Nova Odessa: Editora Plantarum, 1992. $352 \mathrm{p}$.

MARCHIORI, J.N.C. Estudo anatômico do xilema secundário e da casca de algumas espécies dos gêneros Acacia e Mimosa, nativas no Estado do Rio Grande do Sul. 186f. Dissertação (Mestrado em Engenharia Florestal) - Universidade Federal do Paraná. Curitiba, 1980.

MARCHIORI, J.N.C. Anatomia da madeira de Eugenia involucrata DC. (Myrtaceae). Ciência e Natura, Santa Maria, v. 6, p. 127-136, 1984.

MARCHIORI, J.N.C. Estudo microscópico da madeira de sete-capotes, Campomanesia guazumaefolia (Camb.) Berg, Myrtaceae. Ciência Rural, Santa Maria, v. 28, n. 1, p. 47-51, 1998.

MARCHIORI, J.N.C.; SANTOS, S.R. dos. Anatomia da madeira de duas espécies de Eugenia $\mathrm{L}$. (Myrtaceae). Balduinia, Santa Maria, n. 21, p. 15-21, 2010. 
MARCHIORI, J.N.C.; SOBRAL, M. Dendrologia das Angiospermas: Myrtales. Santa Maria: Ed. da UFSM, 1997. 304 p.

MARQUES, P.A.; ARAÚJO, G.U.C.; BARROS, C.F.; CALLADO, C.H. Anatomia do lenho de três espécies de Eugenia L. (Myrtaceae) de mata e restinga. Revista Brasileira de Biociências, v. 5, p. 801-803, 2007.

MATTOS, J.R. Myrtaceae do Rio Grande do Sul. Roessléria, Porto Alegre, v. 5, n. 1, p. 75-163, 1983.

METCALFE, C.R.; CHALK, L. Anatomy of the Dicotyledons. Oxford: Clarendon Press, 1972. $1500 \mathrm{p}$.

RODRIGUES, T.T. Os efeitos do solo contaminado com petróleo na estrutura anatômica e estado nutricional do lenho jovem de Campomanesia xanthocarpa Berg (Myrtaceae) e Sebastiania commersoniana (Baillon) Smith \& Downs (Euphorbiaceae). Tese (Doutorado) - Universidade Federal do Paraná, Curitiba, 2005.
SANTOS, S.R. dos; MARCHIORI, J.N.C. Anatomia do xilema secundário de Eugenia mansoi $\mathrm{O}$. Berg (Myrtaceae). Balduinia, Santa Maria, n. 16, p. 6-12, 2009a.

SANTOS, S.R. dos; MARCHIORI, J.N.C. Anatomia da madeira de Eugenia uniflora L. (Myrtaceae). Balduinia, Santa Maria, n. 17, p. 11-16, 2009b.

SANTOS, S.R. dos; MARCHIORI, J.N.C. Caracterização microscópica do lenho de Campomanesia xanthocarpa O. Berg (Myrtaceae). Balduinia, Santa Maria, n. 18, p. $10-14,2009 \mathrm{c}$.

SOBRAL, M. A família Myrtaceae no Rio Grande do Sul. São Leopoldo: Editora Unisinos, 2003. $215 \mathrm{p}$.

SOFFIATTI, P.; ANGYALOSSY-ALFONSO, V. Estudo anatômico comparativo do lenho e da casca de duas espécies de Eugenia L. (Myrtaceae). Revista Brasileira de Botânica, São Paulo, v. 22, n. 2, p. 175-184, 1999. 